\title{
PROACTIVE MEASURES OF GOVERNMENTAL DEBT GUARANTEES TO FACILITATE PUBLIC-PRIVATE PARTNERSHIPS PROJECT
}

\author{
Hui Ping TSERNG ${ }^{\mathrm{a}}$, Shih-Ping $\mathrm{HO}^{\mathrm{a}}$, Jui-Sheng CHOU ${ }^{\mathrm{b}}$, Chieh $\mathrm{LIN}^{\mathrm{a}, \mathrm{c}}$ \\ ${ }^{a}$ Department of Civil Engineering, National Taiwan University, Taipei, Taiwan \\ ${ }^{b}$ Department of Civil and Construction Engineering, \\ National Taiwan University of Science and Technology, Taipei, Taiwan \\ ${ }^{c}$ Department of Technology, Public Construction Commission, Executive Yuan, Taiwan
}

Received 26 Jul 2011; accepted 20 Jan 2012

\begin{abstract}
Governmental Debt Guarantees (GDGs) are often used to encourage involvement by promoters and financial institutions in Public-Private Partnerships (PPP) projects. However, even after demonstrating the bankability of a project and reducing debt cost, the success of the project may be prevented by the lack of long-term commitment from shareholders. Equity contributions by promoters in the project company may be recovered from earnings on short-term construction activities. Based on lesson learned from early PPP projects with GDG, the hold-up problem for government in the view of transaction cost economic (TCE) theory may worsen if the designed contractual structure does not adequately manage opportunistic behaviours from promoters. This study empirically examined the effects of a structured GDG mechanism with particular complementary measures applied in joint projects to develop the Taipei Mass Rapid Transit (MRT) stations. A GDG game model was then applied to bridge the theoretical gap based on the Taipei MRT experience. The analysis shows that requiring the promoter to provide sufficient equity and ensuring the commitment of the lender to provide the loan are the appropriate proactive measures. This study demonstrates its practical value for policy makers by combining case study, TCE and game theory in contractual issues.
\end{abstract}

Keywords: Public-Private Partnerships, transaction cost economics, game theory, finance, Governmental Debt Guarantee.

Reference to this paper should be made as follows: Tserng, H. P.; Ho, S.-P.; Chou, J.-S.; Lin, C. 2014. Proactive measures of Governmental Debt Guarantees to facilitate Public-Private Partnerships project, Journal of Civil Engineering and Management 20(4): 548-560. http://dx.doi.org/10.3846/13923730.2013.801883

\section{Introduction}

The role of Public-Private Partnerships (PPP) in providing public services has become a common alternative for policy makers around the world (Ock et al. 2005; Russell et al. 2006; Sungmin et al. 2009; Cheung et al. 2010; Tang et al. 2010; Yuan et al. 2010). According to the Private Participation in Infrastructure Database (WorldBank 2010), investment commitments in PPP road projects grew from US\$ 7 billion in 2005 to a new peak of US\$ 16.7 billion in 2008. Solino and Vassallo (2009) also observed that private participation in metropolitan railroads through PPP method has gained the support of local government due to the large and burdensome upfront investment costs.

Although the public sector is risk-averse and tries to transfer most of risks to private in many PPP projects (Yuan et al. 2010), government support for such projects is common in both developing and developed countries, and is deemed as one of the critical success factors (Chen, Doloi 2008; Chowdhury, Charoenngam 2009; Cheung et al. 2010). The literature proposes several explanations for this governmental decision. However, past studies and practical cases demonstrate that the good intentions of the government support may be misused by the promoter due to moral hazard (Zhang 2005; Ho 2006; Chang, Ive 2007; Irwin 2007). As noted by the OECD (2007), "The public sector needs to realize that public guarantees of private commercial behaviour can affect not only the degree of risk allocation and the reporting of the investment as on or off budget, but, more importantly, it can greatly affect the incentives of the private sector to accomplish operational and administrative efficiencies."

Due to the highly diverse forms of government support, this study focused on the Governmental Debt Guarantee (GDG). Because the GDG is the key consideration of lenders when making loans to private promoters, it significantly improves the bankability of PPP projects (PPIAF 2009). However, implementing a GDG is a major challenge due to the increased financial exposure of the government.

As Tang et al. (2010) argued when the government provides too much guarantee, it would be easy for the concessionaire to get the benefit from the contract at the expense of the public. This side effect of GDG to the government is well known to the PPP experts, and a quick 
solution according to their experience is to ask for a "sufficient" equity investment from the promoter. Instead of this intuitional and empirical answer, a literature review reveals the rationales have not been systematically reviewed in a scientific manner. Subsequently, what level of equity investment shall be considered as sufficient (i.e. $20 \%$ or $30 \%$ ) to mitigate opportunistic promoter behaviour in the case of GDG has not been well examined. Few studies have proposed a practical and quantitative method for the determination of this minimum equity requirement from the government perspective. Moreover, what an aggressive role the lenders can request from the government perspective (as a debt guarantor) is also lack of discussion. Thus, more research should be designed to find such an answer to facilitate the success of PPP projects.

Therefore, this study is aimed at exploring the proactive measures from the government perspective that could be embodied in the contractual arrangements among the government, promoters and lenders in a GDG to mediate counter party's opportunistic behaviour and to enable a win-win-win situation. The scope of this GDG pilot study about promoter opportunism is limited to the construction phase since lessons learned from early projects suggest that the government can be taken advantage of easily by profit-oriented promoter's behaviour in the construction phase as presented in the next section.

This paper is divided into below sections. Following the introduction, a literature survey is performed to identify the rationale, potential benefits and problems of GDG in the scientific context of Transaction Cost Economics (TCE) theory. Next, the research design is briefly introduced. The Assistive Financing Mechanism adopted by the Taipei City Government in twelve station PPP projects serves as a case study in Section 3. Section 4 applies game theory to extract valuable knowledge from the case study in a generic form and construct a novel GDG model of quantitative conditions that encourage promoter honesty. Based on the empirical case and developed model, Section 5 presents feasible measures toward the promoter and the lender for harmonizing GDG provisions. Finally, conclusions are drawn, and managerial implications and suggestions for future study are given.

\section{Review of literature on Governmental Debt Guarantee}

\subsection{Why GDG}

The importance of public support in promoting PPP projects successfully is well acknowledged among policy makers, industrialists and academics. For instance, public infrastructure mega-projects are usually associated with huge capital investments and cannot be financially freestanding from user charge while maintaining sustainable fare policies (Devapriya 2006; Irwin 2007; MandriPerrott, Menzies 2010). Other current challenges to successful PPP project delivery include limited access to project finance markets in developing countries (Chen, Doloi 2008; Marin 2009), the bargaining outcome of best risk allocation (Medda 2007; Chowdhury, Charoenngam 2009), and the preference of lenders and the private sec- tor for financing strategies that mitigate political risk or financial risks (Devapriya 2006; Medda 2007). For example, Xu et al. (2010) concluded that the top two risk groups of PPP highway projects in China were government intervention and government maturity risk. Such public support may include equity investment, tax and customs reduction, minimum revenue guarantees, loan provision, capital subsidy and GDG (Zhang 2005; Wibowo 2006; Irwin 2007; Chowdhury, Charoenngam 2009; Mandri-Perrott, Menzies 2010); and thus, facilitate the progress of PPP projects.

Salman et al. (2007) observed that the common challenge for PPP decision makers is to answer the question: "what are the conditions needed and steps to be taken to improve project's viability?" That is because many Build-Operate-Transfer (BOT) projects, one common form of PPP, failed to be completed or were suspended because their prior feasibility studies were insufficient to conclude the viability of the entire undertaking. Furthermore, 21 significant factors which have a certain impact on the feasibility of any BOT project were identified and classified into three categories: legal and environment, financial and commercial as well as technical aspects. Notably, expert opinions collected by their research indicated that the financial and commercial category of project viability factors is the most important $(60.3 \%)$.

Two recent studies (Carrillo et al. 2008; Chan et al. 2010) reported that the difficulty of finding financial partners due to their limited interest is a key obstacle to PPP. Thus, the long and complex procurement process, from preferred bidder stage to financial closing stage, may cause substantial delays. Lenders with limited knowledge of PPP prefer other investment alternatives (e.g. bond issues) than giving loan to PPP projects unless their loan is well secured. Lenders clearly consider GDG the second most important factor (after economic viability) in their decision to lend because it reduces their risk in PPP financing (Chiang, Cheng 2009). Even in the UK, which has a well-developed financial market, direct government support for debt is the preferred method for quickly implementing PPP in exceptional circumstances. After the global financial market was seriously impacted by the 2008 Financial Crisis, the UK government (HM Treasury 2009) temporarily intervened in PPP projects for which sufficient debt financing could not be raised on acceptable terms. Specifically, GDG strategy significantly reduces the lender risk premiums associated with a loan and can increase the financial viability of the project (Wibowo 2006; PPIAF 2008; Tang et al. 2010); therefore, GDG facilitates timely delivery of PPP projects from the possible delay in loan acquisition.

\subsection{Problems caused by GDG in the view of transaction cost economics theory}

\subsubsection{Transaction cost economics}

Transaction cost economics (TCE) was introduced by the publication of "The Nature of the Firm" by Ronal Coase in 1937. "Transaction cost" refers to the cost of using the 
price mechanism or the cost of carrying out a transaction by means of an exchange on the open market. North (1990) proposed that the key transaction cost is the cost of acquiring information which consist of the costs of measuring the valuable attributes of what is being exchanged and the costs of protecting rights by policing and enforcing agreements. Williamson (1996) then proposed that all transactions between two parties involve hidden expenses called transaction costs based on the assumption that human beings are bounded rationality and sometimes display opportunistic behaviour.

Briefly, any exchange between two parties is a transaction. Division of labour and specialization encourages transactions in society (Dougma, Schreuder 2002). For example, completing the PPP project required coordination among the government agency, promoter, designer, contractor, lender, and operator. Each economic exchange between these participants represents a transaction. From the TCE perspective, transactions occur across markets or within organizations (defined as hierarchies). Whether a transaction is allocated to the market or to a hierarchy is a matter of cost minimization. Notably, transaction costs should be considered because total cost is the sum of traditional production costs and transaction costs (Grunegerg, Ive 2000). Comparing the costs of managing transactions internally and externally may indicate whether the goods or services should be produced in house (defined as hierarchy) or purchased on the market. The TCE also enables the design of an improved hybrid governance structure between market and hierarchy (e.g. different contracts or organizations) that reduces transaction costs. The TCE provides a conceptual framework for enhancing economic performance by designing governance structures that reduce transaction costs.

Dudkin et al. (2005) concluded that procurementphase (including bidding and contract negotiation) transaction costs comprise over 10 percent of the capital value of PPP projects. In post-contract stage, the likelihood of incomplete contracts usually increases in long and complex PPP projects. Therefore, anticipating all possible events during the project lifetime is difficult. Some contractual agreements designed to maximize ex-ante efficiency may result in ex-post inefficiency since the value of the contract performance to the promise is lower than the cost of performance incurred by the promisor (Solino, Vassallo 2009). The opportunistic behaviours of individual parties trying to exploit a situation for their own advantage increase the potential for high transaction costs in the post contract stage of PPP projects, which is known as the hold-up problem (Zhang 2005; Ho 2006; Chang, Ive 2007; Irwin 2007; Ho, Tsui 2010).

When two contracting parties enter the post-contract stage, both try to maximize their own profits by opportunistically exploiting unforeseen events that are not governed by the original contract. The party that tends to be disadvantaged is the one that has less bargaining power and is susceptible to the hold-up problem. This occurs because bargaining power is inversely related to the commitments/investments of a party to that particular transaction (e.g. PPP project). In this inverse relationship, the so-called asset specificity problem is that the counter party can credibly threaten to terminate the transaction (project), which can cause a huge loss, especially if the value of alternative uses for the commitments/investments is relatively small. Briefly, hold-up refers to action by the counter party to exploit the situation and to appropriate the expected profit by threatening to walk away from the relationship.

The model proposed by Chang and Ive (2007) captured the increased vulnerability of project owners in the post-contract stage when the initial requirements must be changed after signing the contract and when transaction costs are high. Specifically, when the owner issues a change order, the contractor tends to ask for a price higher than the general market price because the contractor knows that the owner is held up. The owner tends to accept the price demanded by the contractor unless the cost of acceptance exceeds the cost of any one of the following: 1) the loss incurred by abandoning the work in progress; 2) the cost of switching to another contractor; or 3) the cost of using dispute resolution mechanism plus the cost of settlement. To avoid delay and further costs, the owner usually prefers not to abandon the construction-in-progress, let alone switch contractors or use a dispute resolution mechanism. Therefore, the party with less bargaining power may take expensive measures to mitigate vulnerability to the hold-up problem, which thus increases transaction costs.

In this discussion, governance structure refers to the GDG direct agreement among the government, the Project Company funded by the promoters, and the lender. It determines the relationship between interested parties after a termination or threatened termination due to Project Company Default. In this study, TCE is used to explore the proper governance structure (the direct agreement) that harmonizes government transaction costs in PPP projects with GDG.

\subsubsection{Reduced cost borne by the promoter under GDG}

A PPP project is typically financed by a combination of equity and debt. Equity holders (Promoters) are entitled to share in profits but may only do so after lenders receive their due interest. In a winding up, they are entitled to the balance of the realized net assets after lenders have been paid; thus, promoters may get nothing in return for their investment in bad times. Therefore, the amount of their investment determines the value of their assets specific to the success of the PPP project in which they invested.

Despite the benefits of GDG, the promoter's long term commitment to the performance of PPP project with GDG shall be significantly reduced if the contractual arrangement (i.e. governance structure) is poorly designed. Specifically, the construction profit-oriented behaviour by promoters is encouraged. Figure 1 shows that, when a PPP strategy is used in transportation construction projects, contractors and rolling-stock providers are often the promoters in the consortium. Because they are the major Project Company shareholders, the sub-contracts for construction work and equipment are normally awarded to them at prices above market prices due to the lack of open compe- 
tition (Ho, Tsui 2010). Such promoters are considered short-term investors (Zhang 2005) because their equity contributions to the Project Company are generally recovered from earnings on construction activities.

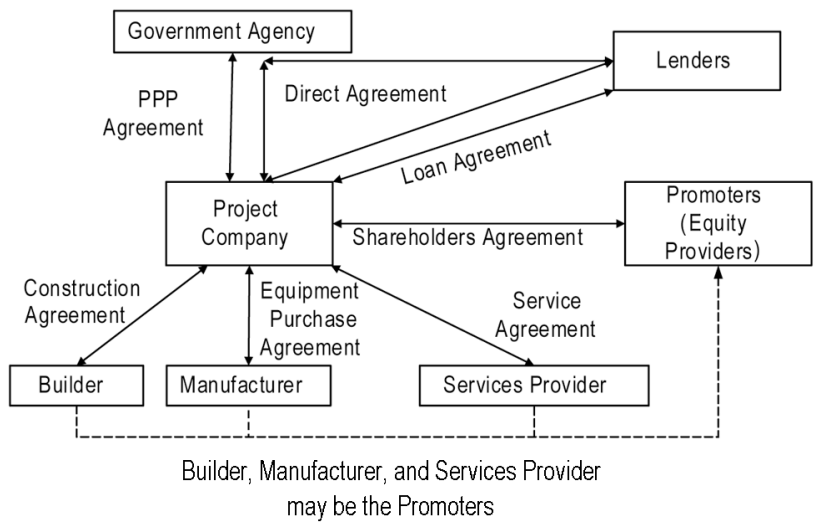

Fig. 1. A representatively contractual framework among stakeholders in PPP

The literature also indicates that such governmentbacked projects often "deteriorate" because the promoter tends to exaggerate the debt-carrying capacity of the project whereas the lender may not examine the project rigorously. The lack of due diligence often results in financing with a high debt-to-equity ratio, which enables shortterm promoters to undertake large construction activities with small equity contributions.

Askar and Gab-Allah (2002) argued that a minimum (or reasonable) level of equity is generally needed to convince the lender that the project is creditworthy and therefore bankable and financeable. Bakatjan et al. (2003) later developed a program for optimizing the capital structure of BOT projects from the "promoter" perspective. That is Debt Service Coverage Ratio (DSCR), i.e. the ratio of annual cash available at hand to annual total debt service. Sungmin et al. (2009) presented a model to optimize the developer's equity level for privately financed infrastructure projects via Monte Carlo simulation. Furthermore, an appropriate concession period can be deduced basing on the fuzzy simulation model proposed by $\mathrm{Ng}$ et al. (2007) or the simulation-based approach proposed by Zhang and AbouRizk (2006). However, none of them has proposed a practical and quantitative method to the government for the determination of minimum equity investment from the promoter.

\subsubsection{Increased transaction costs borne by the government agency under $G D G$}

Abandoning a PPP project is rarely feasible because of the huge loss of socio-economic-political benefits. Moreover, to reap such benefits, the public sector always strives to complete the project and to provide the service on time. Thus, given the long duration and complexity of a PPP, both the cost of switching promoters and the cost of using dispute resolution mechanisms are higher than those in ordinary construction projects because of time constraints.
Particularly, for a PPP project with GDG, the government immediately bears the huge debt liability should it choose to terminate the contract either after a promoter default or after an unforeseen event that is advantageous to the promoter. Therefore, as asset specificity increases, the transaction costs and the vulnerability of the government also increase. In a GDG without a well-designed governance structure, hold-up problem for the government agency is worse than that in an ordinary construction or PPP project because the asset specificity of promoters is reduced whereas that of the government is increased.

\subsection{Real cases facing problems caused by GDG}

Indeed, whether to provide GDG in PPP projects is a major policy dilemma. One representative case is the Taiwan High Speed Rail BOT Project (THSRP). In the financial package proposed by the consortium (MOTC 2010), total capital investment was US\$ 13.54 billion financed through equity (US\$ 3.45 billion) and debt (US\$ 10.09 billion). During contract negotiations, the government authority agreed with the consortium that no lender should lend money without a GDG. Thus, the direct agreement signed by the government authority, Project Company, and lenders set the bailout cap at US\$ 10.83 billion (Li 1998). The agreement for the US\$ 10.74 billion loan to the Project Company was then signed. According to the government authority, the GDG for the THSRP was justified by the vast social and economic benefits expected from the project. It avoided delays caused by switching to alternative procurement approaches. The internal and external values of early completion to the public clearly outweigh the contingent government liability.

However, controversy happened during the building phase. An official report by the Control Yuan, which is the highest auditing organization in the Taiwan government, indicated that a THSRP promoter undertook US\$ 854 million in construction work whereas its equity contributions to Project Company were only US\$ 139.5 million. Because the initial equity investment from the consortium members corresponded to only about $6 \%$ of the loan the Project Company eventually took out, it may give the members only a modest sum at risk, compared to construction profits they earned. Subsequently, the promoters were reluctant to inject any money when the government asked them to honour the contractual requirement of one-quarter equity. Eventually, this equity gap was invested by stateowned companies and government-controlled banks. Another case is the railway guarantees in Russia (Irwin 2007), which encouraged Project Company managers appointed by the controlling shareholders to exploit the Project Company and the government agency by paying inflated prices to suppliers and construction companies belonging to controlling shareholders.

\section{Research design}

The research framework of this study included "case study approach" and "game theory analysis". Firstly, a series of Taipei Mass Rapid Transit (MRT) station PPP projects with a particular GDG mechanism serve as the exploratory cases. These cases provide valuable insights 
in dealing with the hold-up problem facing the government in a GDG. However, where studies relied on case study only, the further application of their findings are usually restricted because contract arrangements are project specific and sensitive to the different context of the host country.

In this sense, following the findings from case study, the research process was continued by modelling the GDG on the basis of game theory. The advantage of introducing a game-theoretic approach, as noted by Aoki (2008), is the intuitively appealing and plausible notion that institutional interdependencies, coherence and robustness are considered analytically tractable rather than ad hoc presumptions. Notably, game theory serves as a vehicle to extract the underlying principles from the Taipei metro practitioners' experience; therefore, the constructed model is generic and can broaden its application scope to other types of PPP projects in other countries.

Game theory can be defined as the study of mathematical models of conflict and cooperation between intelligent rational decision-makers (McCain 2004). It provides a systematic and conceptual framework for optimizing the strategy of a participant in response to the strategies of all other participants (Ho 2006). All players are assumed to be rational and self-interested in their pursuit of maximum payoff. There are two basic types of games: static games and dynamic games, in terms of the timing of decision making. In a static game, the players act simultaneously, meaning that each player chooses his/her action without knowing others'. On the contrary, the players act sequentially and observe other players' actions in previous moves in a dynamic game. Because the promoters make the decisions on the sharing of knowledge after observing the GDG option taken by the government, the dynamic game will be used for modelling and analysis in this study.

In order to answer what each participant will behave in this GDG game, the concept of "Nash equilibrium", one of the most important concepts in game theory is introduced. The Nash equilibrium is a set of actions that will be chosen by each player. In other words, in the Nash equilibrium, each player's strategy should be the best response to the other player's strategy, and no player wants to deviate from the equilibrium solution. Thus, the equilibrium or solution is "strategically stable" or "self-enforcing" (Gibbons 1992). In a dynamic game, the Nash equilibrium is a subgame perfect Nash equilibrium, which satisfies the sequential rationality required for the solution of a dynamic game. For more information about the game theory analysis and its application, readers are suggested to refer to Ho et al. (2011) and Tserng et al. (2012).

\section{Case study}

\subsection{Background of Taipei MRT station PPP cases}

After about 20 years development, the network of Taipei MRT lines that have been completed for commercial service is $106.4 \mathrm{~km}$, with over 1.3 million passenger trips per day on average (DORTS 2011). In order to release the huge financial burden of the government during the con- struction, property development around/above MRT stations was considered as a feasible solution to internalize the external benefit that results from investments in MRT system. Moreover, those stations can also be built by the property developers without the money coming from the government's pocket. A dedicated regulation was established (e.g. Regulation for the Development of Land Adjacent to or Contiguous with MRT System) at the beginning to form the legal basis covering related issues of planning, application, evaluation, land acquisition, land use, guarantee bonds, incentives, monitoring, etc.

From the perspective of the Taipei City Government, the ideal scenario for enhanced cost-effectiveness and efficiency is for landowners to offer land and for promoters to fund the integral planning, design and construction of the MRT stations. This joint-development approach which belongs to the PPPs concept reduces the financial burden on the Government and applies the skills and knowledge of promoters, which may not be available from the public sector. Although this idea was implemented, the results were disappointing. One major reason was that the promoters had difficulty obtaining loans because banks were unfamiliar with the novel proposal and were reluctant to make non-collateralized loans.

Thus, the Taipei City Government proposed an assistive financing mechanism, a particular form of GDG, in 2003 after one year preparation and communication with promoters and bankers. As of the end of 2010, promoters in twelve station projects have used this mechanism to obtain more than US\$ 898.9 million in loans as summarized in Table 1. They are Muzha Station, Yongchun Station (Zone 19), Yongchun Station (Zone 21), Houshanpi Station (Zone 25), Taipei Main Station (T 9), Xindian City Office (Zone 22), Qizhang Station (Zone 10, 11), Wanlong Station (Zone 10), Gongguan Station (Zone 11), Xingtian Depot (Zone 17, 18, 19), Xingtian Temple Station (Zone 5) and Xingtian Temple Station (Zone 7).

The assistive financing mechanism used in these twelve station projects was selected as an exploratory case for the following two reasons: firstly, of these twelve projects, nine were successfully delivered while three are currently nearing completion. Until now, none has been terminated early, and, therefore, none has required a government bailout. The successful use of this assistive financing mechanism confirmed its validity.

Secondly, in order to insure that all participants fulfil their contractual obligations without failure, a trust organization is used which form a particular contractual complexity beyond what is considered standard practice in PPP projects. As presented in Figure 2, the contractual framework including "PPP Agreement", "Loan Agreement", "Direct Agreement" and "Trust Agreement" is more complex than that of common PPP projects as presented in the upper part of the Figure 1 (without Trust Agreement).

The results of the case study, which included a detailed review of official meeting minutes and terms of direct agreement and trust agreement, in conjunction with face-to-face interviews with basic-level and high-ranking officials responsible for establishing and implementing the assistive financing mechanism, are given below. 
Table 1. List of Taipei MRT station joint-development projects with assistive financing mechanism (until the end of 2010)

\begin{tabular}{|c|c|c|c|c|c|c|c|}
\hline \# & Line & Joint-development Station & $\begin{array}{c}\text { Base Area } \\
\left(\mathrm{m}^{2}\right)\end{array}$ & $\begin{array}{c}\text { Floor Area } \\
\left(\mathrm{m}^{2}\right)\end{array}$ & $\begin{array}{c}\text { Total } \\
\text { Investment } \\
\text { (US\$ million) }\end{array}$ & $\begin{array}{c}\text { Debt with } \\
\text { GDG } \\
\text { (US\$ million) }\end{array}$ & $\begin{array}{c}\text { Actual } \\
\text { Completion } \\
\text { Date }\end{array}$ \\
\hline 1 & Wenshan-Neihu & Muzha Station & 14,251 & 39,733 & 58.4 & 34.6 & Under Construction \\
\hline 2 & Nangang & Yongchun Station (Zone 19) & 2,448 & 23,627 & 18.6 & 16.9 & 31 May 2005 \\
\hline 3 & Nangang & Yongchun Station (Zone 21) & 4,512 & 37,633 & 35.9 & 29.6 & 6 Oct 2005 \\
\hline 4 & Nangang & Houshanpi Station (Zone 25) & 1,533 & 9,341 & 9.4 & 4.9 & 12 May 2006 \\
\hline 5 & Danshui & Taipei Main Station (T 9) & 21,374 & 244,717 & 395.0 & 292.4 & 24 Jul 2009 \\
\hline 6 & Xindian & Xindian City Office (Zone 22) & 1,721 & 13,896 & 21.5 & 8.6 & 29 Oct 2004 \\
\hline & Xindian & Qizhang Station (Zone 10,11) & 7,900 & 89,735 & 140.1 & 73.1 & 9 Jan 2008 \\
\hline & Xindian & Wanlong Station (Zone 10) & 1,248 & 7,680 & 10.3 & 5.0 & Under Construction \\
\hline & Xindian & Gongguan Station (Zone 11) & 1,868 & 15,921 & 28.0 & 15.0 & 29 Dec 2005 \\
\hline & Xindian & Xingtian Depot (Zone 17,18,19) & 92,561 & 405,695 & 652.7 & 394.5 & Under Construction \\
\hline & Luzhou & Xingtian Temple Station (Zone 5) & 2,223 & 17,966 & 31.1 & 18.9 & 12 May 2009 \\
\hline \multirow{2}{*}{\multicolumn{2}{|c|}{12 Luzhou }} & Xingtian Temple Station (Zone 7) & 629 & 4,958 & 9.3 & 5.7 & 5 Jan 2010 \\
\hline & & Total & 152,267 & 910,903 & 1410.4 & 898.9 & \\
\hline
\end{tabular}

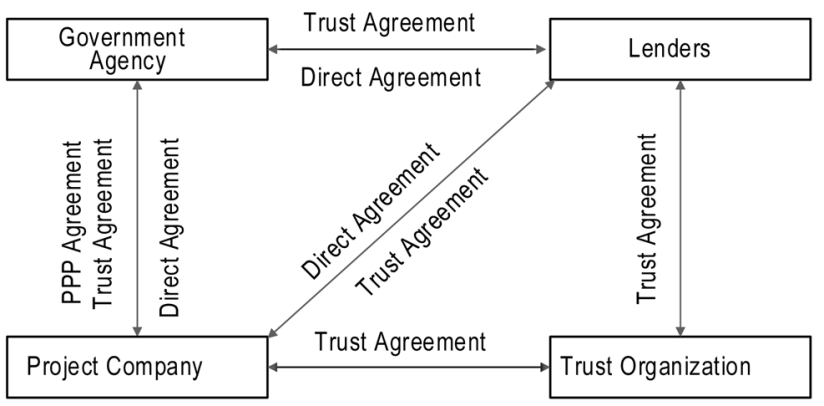

Fig. 2. The contractual framework of Taipei MRT station PPP Project

\subsection{Introduction of assistive financing mechanism}

Figure 3 shows the implementation procedures for the mechanism. The Taipei City Government, the bank, and the promoter in the Project Company contractually agree to how their relationship would be affected by a termination or by a threatened termination after promoter default. Essentially, the Taipei City Government guarantees the loan to the Project Company whereas both the bank and the promoter commit to the following complementary measures.

If a promoter default leads to early termination of the PPP agreement in the construction phase (e.g. if the promoter cannot raise the required equity investment), the City Government "may" terminate the PPP agreement. In this case, the City Government must purchase the workunder-construction at a "compensation payable" purchase price. After deducting a penalty for promoter breach of contract ( $30 \%$ of the agreed "compensation payable", which is equal to total equity investment), the priority of the City Government is to repay the loan to the bank.

Instead of terminating the PPP, the City Government "may" choose to fill the gap in promoter equity. The direct agreement requires the bank to continue disbursing the loan. Upon completing the construction work, the market value of the project should far exceed that at the time of promoter default due to lack of a liquid market for incomplete construction projects. This ensures the completion of the development project, which is the objective of the Government.
The following clauses are added to the PPP agreement to comply with the principles of the above direct agreement: 1) Project Company should entrust all sources of funds (equity from the promoter and loans from the bank) and rights to a trust organization; 2) the bank must be included as a beneficiary of the All Risk Insurance held by the Contractor. The insurance claim must be managed in an individual account and can be used to pay for necessary repairs or reconstruction of target projects. The above trust system has three advantages: 1) The promoter equity and the bank loan are managed in an individual account, which ensures that the Project Company uses the funds appropriately; 2) The actually cumulative expenditures on the construction work are clearly identified, so compensation payable in the event of early termination is easily determined; 3) It prevents lender foreclosures or provisional seizures of the work under construction when the promoter has financial difficulties. Therefore, it limits interruptions of project progress.

Limitations of this mechanism are as follows: 1) The City Government provides GDG in the construction phase only (no revenue guarantee in the operation phase). This mechanism can be considered a government assurance of completion. Fortunately, since the financial pressure on PPP projects is highest in the construction phase before revenue is generated, the limited scope of the application is appropriate in most cases. 2) Although GDG can reduce funding costs, complementary measures such as employment of the trust organization increase administration and monitoring costs. Therefore, the trade-off between capital costs and administration and monitoring costs should be carefully considered. From the perspective of promoters who can secure their own bank financing, GDG is inappropriate because it increases their costs. In the case of the Taipei MRT stations, promoters in about one-third (12 of 39) projects have requested GDGs. 3) The government agency should consider this mechanism a last resort for project financing because the government agency must assume the debt in the worst-case scenario. A thorough evaluation is needed in the planning phase to confirm the financial feasibility and construction costs of the project and to minimize government risk. 


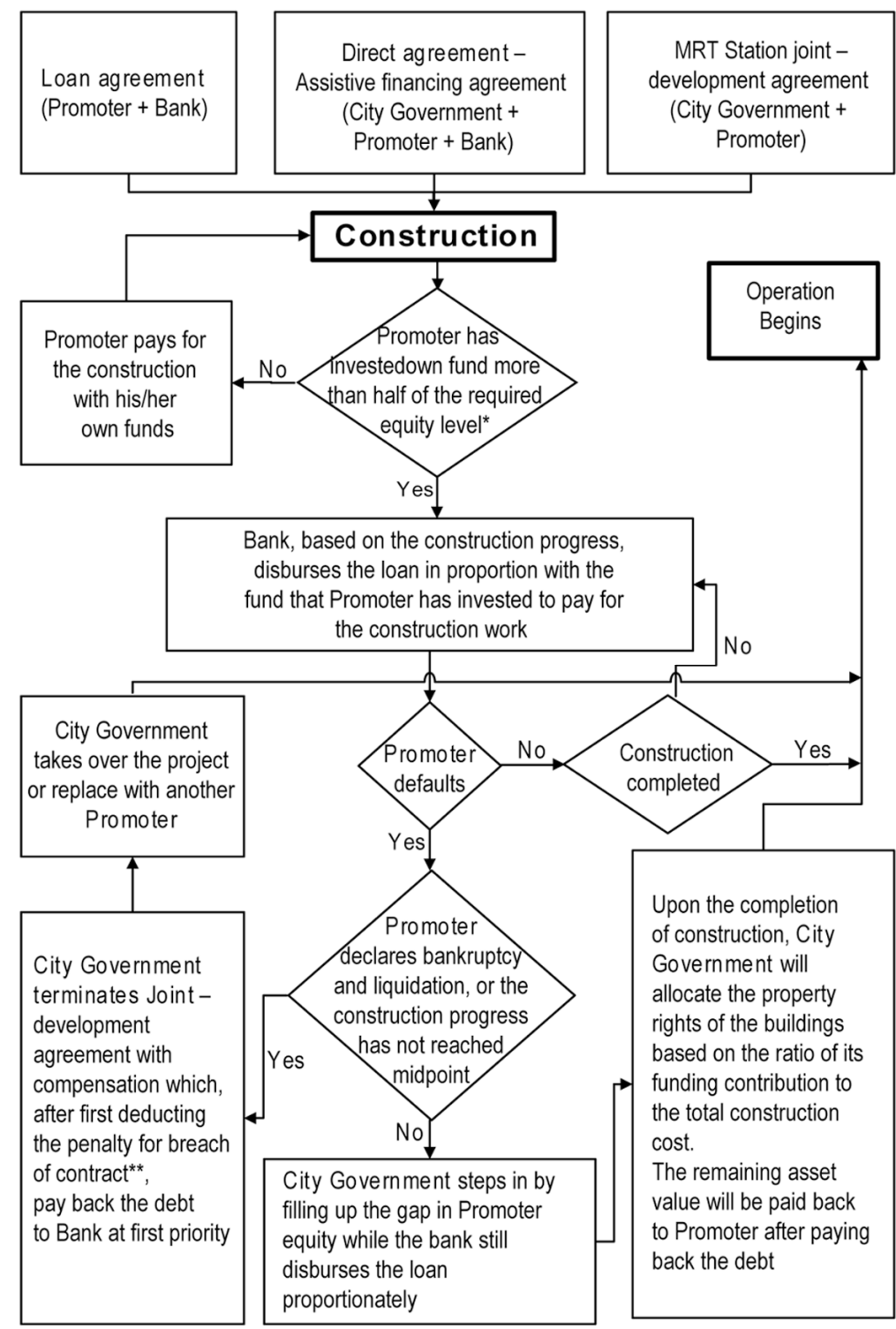

* The equity level is requested to be at least $30 \%$.

** Penalty for breach of MRT Station joint-development agreement is $30 \%$ of the compensation payable which is the lower amount between „planned“ and ,actual“ expenditures on construction.

Fig. 3. Implementation procedures of assistive financing mechanism of Taipei MRT station joint-development project

\subsection{Analysing the underlying principles of assistive financing mechanism}

The authors view this governance structure as a "conditional" GDG. These complementary measures enable the government to balance hold-up and bargaining power when managing the construction profit-oriented behaviour of the promoter and to avoid inheriting the debt left by the promoter.

\subsubsection{Increasing the cost of the promoter}

The transaction cost of the promoter can be increased because the asset specificity of the promoter can be increased in this governance structure. Several approaches are possible:
Appropriately require minimum promoter equity: Promoter equity should be at least $30 \%$. Additionally, the bank should only be allowed to disburse the loan after the promoter commits at least half of the agreed funding. Additionally, the disbursement of loans should be proportional to the amount committed. The rationale is that promoters should kick-off the construction work with their own money. Unless the promoter provides $15 \%$ of total project capital, the bank loan can be used to inject funds proportionally. Regarding why a $30 \%$ equity level is required for Taipei cases, no concrete reason can be found in the documents. Is it too conservative or too risky? A scientific model will be introduced to bridge the empirical findings based on game theory in Section 4, and thus, the "appropriate" minimum equity requirement 
can be determined not only in Taipei cases but also in other PPP projects.

Meaningfully penalize promoter default: The agreed penalty for early termination caused by promoter default is $30 \%$ of payable compensation. The penalty ratio is set intentionally the same as the required equity ratio. If the City Government must take over the project, the invested funds by the promoter become a sunk cost; this increases the asset specificity of a promoter who is considering walking away from a project that is currently underway.

Carefully determine the amount of compensation: If the promoter inflates the construction fee, the City Government overpays for the project. Thus, the amount of compensation payable upon early termination is determined by whichever of the following is lower: 1) Planned expenditures on construction: this amount is based on the investment execution plan approved by the City Government and is the cumulative construction cost as of the time of early termination. 2) Actual expenditures on construction: the trust organization must present receipts from all manufactures and contractors on behalf of the Project Company. A professional and independent third party should be commissioned for due diligence. Finally, these expenditures must be approved by the bank and the City Government.

\subsubsection{Reducing the transaction cost of the government agency}

The switching cost is usually the upper limit of the amount that the promoter can take advantage of the government in the event of ungovernable contingencies (Chang, Ive 2007). The government hold-up problem is reduced because the switching cost is better managed by:

Against the promoter: The penalty for early termination due to promoter default is $30 \%$ of payable compensation. This amount should be sufficient for the government agency to find an alternative promoter.

Against the banker: The direct agreement provides that the City Government can fill the funding gap when the promoter encounters financial difficulties and that the bank must disburse the loan continuously. Thus, the government avoids the immediate budgetary burden of paying out the promoter debt. Moreover, the direct agreement should ensure that the interest rate from this point should be lower than that for the promoter.

\section{The GDG game}

\subsection{Model setup}

The two participants in this game are the Government (GOV) and the Promoter, and the GDG is the security package required by the lender. Accordingly, GOV must first determine whether to provide the GDG. The strategic choices of the Promoter are either honour (by performing the PPP agreement in good faith) or exploit (by hold-up or other opportunistic behaviours). When analysing holdup coupled with construction profit-oriented intention, the associated business of the Promoter is assumed to be relevant to that PPP project (e.g. the contractor or equip- ment provider). Meanwhile, the sub-contracts are awarded to the business associates of the Promoter.

In this sequential game, the GOV moves first, and Promoter observes the GOV action before choosing a strategy. Figure 4 shows the extensive form. Suppose that early termination after Promoter default occurs in the construction phase. The GOV then takes over the project after providing compensation (denoted by EV) to the Promoter, and the Promoter is liable for the agreed penalty, which is equal to the equity level $(\alpha)$. Eqn (1) formulates the relationship, where $A C=$ the actual cost of construction work performed, i.e. total costs incurred by the contractor to complete work during a given time period; $E V=$ the earned value, also called the budgeted cost of construction work performed, i.e. total expenditures paid by the Project Company to the contractor during a given time period; $R C P=$ reasonable construction profit margin when an open tendering procedure is used; $\kappa=$ inflated construction profit margin resulting from limited tendering procedure in which only one contractor is invited to tender an offer for the construction work. Basically, $A C$ and $E V$ used above are drawn from (PMI 2004):

$$
E V=A C(1+R C P+\kappa) .
$$

Other abbreviations are used in the model: $\alpha=$ equity level, equity $=\alpha \times E V$, and debt finance $=(1-\alpha) \times$ $E V ; N P V=$ the expected net present value of the PPP project; $\beta=$ the ratio of project value shared by GOV to $\mathrm{NPV}$, which is decided through open competition of that PPP project; $r=$ interest rate of the debt (since the debt is guaranteed by GOV, where $r$ should approximate the nominal yield of bond depending on the GOV's creditworthiness); $G=$ the smallest GOV subsidy needed to persuade the lending bank to continue supporting a project after Promoter default; $\tau=$ opportunity cost for the GOV to replace the promoter, which may include the retendering cost and the cost of interruption due to the bankruptcy and retendering process; $\lambda=$ cost of administering GDG.

GOV

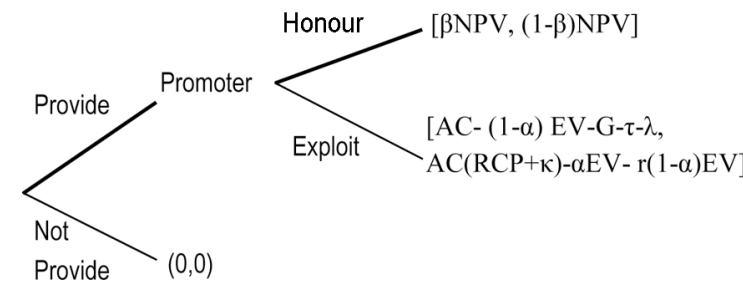

Fig. 4. The extensive form of GDG game

\subsection{Propositions and discussions}

Proposition 1: Where $\alpha>1-\frac{1}{(1-r)(1+R C P+\kappa)}$ the dominant strategy for the Promoter is to honour the contract when GOV chooses to provide GDG.

Proof: A dominant strategy is the strategy that is the best response to all possible strategy choices of all the other players (Carmichael 2005). By direct verification, Pro- 
moter chooses the "honour" strategy only if it yields a higher payoff compared to "exploit". That is:

$$
A C(R C P+\kappa)-\alpha E V-r(1-\alpha) E V<(1-\beta) N P V .
$$

Since GOV and Promoter never promote a project with negative NPV, replace $N P V=0$ (the worst case for GOV) in Eqn (2):

then

$$
\begin{gathered}
A C(R C P+\kappa)-\alpha E V-r(1-\alpha) E V<0 ; \\
A C(R C P+\kappa)-\alpha E V-r E V+r \alpha E V<0 ; \\
A C(R C P+\kappa)-r E V-\alpha(1-r) E V<0,
\end{gathered}
$$$$
\text { then } \quad \alpha(1-r) E V>A C(R C P+\kappa)-r E V \text {, }
$$

substitute Eqn (1) into Eqn (6):

then $\quad \alpha>1-\frac{1}{(1-r)(1+R C P+\kappa)}($ Q.E.D. $)$.

Discussion: Since the contingency is that GDG is provided, the rational Promoter maximizes the payoff. The preferred Promoter response, honour or exploit, depends on which yields the higher payoff. The GOV is suggested to think strategically and to anticipate how a Promoter would respond to the offer of a GDG. In short, Eqn (7) indicates the best protective measure for the government even when NPV equals 0 . The government should request an equity level appropriate for the given values of $r$ RCP and $\kappa$. The outcome (Eqn (7)) of the game proposed in this study can supplement the theoretical gap in the case study, which is based on expert rules of thumb. The simplified formulation applied to the Taipei MRT station experience can be expanded to other PPP projects across different infrastructure sectors.

Proposition 2: Suppose that Proposition 1 holds and that $G, \tau, \lambda$, and $r=0$ for GOV The subgame-perfect Nash equilibrium for GOV and Promoter is (Provide, Honour).

Proof: A Nash equilibrium is subgame-perfect if the player strategies constitute a Nash equilibrium in every subgame (Gibbons 1992). The authors solve this game by backwards induction as follows. Because Proposition 1 holds, the unique solution for the Promoter optimization problem in the second stage of the game is honour. Since GOV can anticipate the Promoter reaction to each GOV action at the first stage, the GOV must decide how to maximize its payoff. Briefly, the "provide" strategy shall be a dominant strategy if it yields a higher GOV payoff compared to the "not provide" strategy. Since BNPV [the corresponding payoff for GOV for (provide, honour)] exceeds 0 [the payoff for GOV at not provide], provide must be the dominant strategy for GOV if AC $-(1-\alpha)$ $\mathrm{EV}-\mathrm{G}-\tau-\lambda$ [the payoff for GOV at (provide, exploit)] is no less than 0 [the payoff for GOV at not provide]. Because Proposition 1 holds, Eqns (1) and (7) above are substituted into Eqn AC $-(1-\alpha) \mathrm{EV}-\mathrm{G}-\tau-\lambda$; moreover, if $G, \tau$, and $\lambda=0$, then:

Payoff

$$
\mathrm{GOV}=1-\frac{1}{(1-r)}
$$

If $r=0$, then Payoff GOV $=0$ (i.e. provide is the dominant strategy for GOV).

Therefore, the backwards-induction outcome of this game is (provide, honour) with the corresponding payoffs $[\beta N P V,(1-\beta) N P V]$. Further, in this two-stage game of complete and perfect information, the backwardsinduction outcome is the subgame-perfect Nash equilibrium defined by Gibbons (1992) (Q.E.D.).

Discussion: The assumptions in Proposition 1 and Proposition 2 protect the GOV from the pitfalls of a GDG. The exploratory cases demonstrate a practical application of these theoretical assumptions. The direct agreement commits the lending bank to disbursing the loan only if the City Government chooses to step in $(G=$ 0 ). Additionally, the Promoter penalty is equal to the project equity $(30 \%)$, which should adequately compensate the City Government for the total costs of replacing the promoter, administering the government guarantee, and paying the interest on the debt $(\tau, \lambda$, and $r=0$, respectively). If the lender or promoter declines to commit, GOV has no dominant strategy because its payoff from "provide" may be smaller than that from "not provide". Thus, the game may be terminated, meaning both the participants and the lender leave with "zero" payoff. To obtain a win-win-win outcome (i.e. [ $\beta N P V,(1-\beta) N P V$, $r(1-\alpha) E V])$ among GOV, Promoter and the lender, the best response by the three participants is agreeing to the above complementary measures because the payoff matrix of this cooperative solution outweighs that of noncooperation.

\section{Suggested proactive measures and applications}

According to the literature, case study and theoretical model, the transaction cost resulting from asset specificity for the government, the promoter and the lender can be balanced concurrently in GDG by a properly designed governance structure. The government should request all participants to commit to the project unanimously. The payoff matrix (i.e. [ $\beta N P V,(1-\beta) N P V, r(1-\alpha) E V]$ among GOV, Promoter and the lender) for this cooperative solution shows that the bonding arrangement under the proposed scheme benefits all participants.

\section{Requesting sufficient promoter equity}

In accordance with proven proposition 1 and innovative Eqn (7), the sufficient equity level of the promoter should be required by the government can be calculated based on $r$, RCP and $\kappa$. The value of $r$ (the interest rate of the debt) can be set to the nominal yield of government bonds. That is because they are guaranteed by the government as well. In this case, the default risk of the debt perceived by the lenders should be similar to that of the government bond. Therefore, a similar risk premium is required. The value of RCP can be set to the average profit margin of listed companies whose main business is relevant to the construction work, such as building contractors, civil engineering contractors, design-build firms, etc. The value of $\kappa$ can set to the average ratio of tender awarding value to budget value in previous government procurement projects. The GOV can also apply the cost 
estimation tools and techniques proposed in the PMBOK Guide (PMI 2004), including analogous estimating, parametric modelling, bottom-up estimating, and computerized tools, in order to estimate $\kappa$ accurately. Table 2 is a minimum equity level matrix for $r=2 \%$. For example, if $\mathrm{RCP}$ and $\kappa$ equal $10 \%$ and $30 \%$, respectively, the government should require minimum promoter equity of $27 \%$. The proposed equation is not only practicable for policy makers but also scientifically proven as a selfenforcing Nash equilibrium which can avoid the subjective or intuitional determination based on rules of thumb.

Table 2. Matrix of equity levels $(\alpha)$ by reasonable construction profit margin (RCP) and inflated construction profit margin $(\kappa)$ with fixed interest rate

\begin{tabular}{ccccccccccccc}
\hline \multirow{2}{*}{$\begin{array}{c}\alpha(\%) \\
(r=2 \%)\end{array}$} & 0 & 10 & 20 & $\underline{30}$ & 40 & 50 & 60 & 70 & 80 & 90 & 100 \\
\hline \multirow{2}{*}{$\mathrm{RCP}$} & $\frac{10}{20}$ & 7 & 15 & 22 & $\underline{27}$ & 32 & 36 & 40 & 43 & 46 & 49 & 51 \\
$(\%)$ & 20 & 22 & 27 & 32 & 36 & 40 & 43 & 46 & 49 & 51 & 54 \\
& 30 & 22 & 27 & 32 & 36 & 40 & 43 & 46 & 49 & 51 & 54 & 56 \\
\hline
\end{tabular}

The detailed contract arrangements drawn from the exploratory cases can then be considered in line with the characteristics of each PPP project application. For example, the penalty for breach of contract can be based on the required minimum equity level; the payable compensation can be set to planned or actual expenditure, whichever figure is lower. The Project Company should also entrust its funds and rights to a trust organization through the trust agreement.

\section{Preventing lender withdrawal}

Proposition 2 which has been proven suggests that measures complementary to a GDG should manage the government's cost of persuading the lender to continue supporting a project after promoter default $(G)$. Since it must pay out the secured debt immediately, the government is vulnerable to a lender exercising its power to withdraw funds. The detailed contractual structure in the case study shows that, if the government chooses to take over a project, the lender should be obligated to continue providing the loan. The interest rate should also be determined in advance.

\section{Conclusions}

The public sectors should refine their strategies for delivering better Public-Private Partnerships (PPP) projects by reviewing empirical cases and theoretical foundations given the fact that PPP is now used to finance infrastructure projects worldwide. In order to prevent the financial bailout of the government from the promoters' opportunistic behaviour in a Governmental Debt Guarantee (GDG) PPP project, this study used case study and game theory for developing generic and proactive measures for the government that complement GDG in the construction phase. This generic GDG model and suggested proactive measures have been proven based on game theory as a selfenforcing Nash equilibrium. This model can bridge the theoretical gaps in the case study and broaden its application.
Contractual arrangements for two proactive measures against to the promoter and the lender respectively are proposed to enable policy makers to mitigate their financial exposure risk in GDG. The authors propose an innovative and practicable equation for quantitatively calculating the minimum equity level of the promoter should be requested by the government in response to $r$ (interest rate of the debt), RCP (reasonable construction profit margin through open tendering procedure) and $\kappa$ (inflated construction profit margin resulting from limited tendering procedure). The government should require the promoter to meet this minimum equity level. Instead of requiring the government to pay out the secured debt immediately, the contract should also require the lender to continue providing the loan if a government takeover occurs after promoter default.

According to transaction cost economy (TCE), the suggested measures complementary to GDG can harmonize the transaction costs of the government agency. However, both the transaction costs of the promoter and the lenders resulting from asset specificity increase concurrently. Briefly, the proposed governance structure is a mutual hold-up structure. Since all parties involved increase their commitments, the proposed contractual arrangements give all parties an incentive to make the project work by placing their investment at risk. Notably, GDG is one out of many types of government supports for PPP. All participants should recognize the pros and cons of each type of government support; and furthermore, choose the proper type of government support according to the attributes of each project.

The findings of this study are valuable for both PPP experts and researchers. In practice, the conceptual idea that a minimum equity investment is essential to the success of a PPP project based on rules of thumb has been enhanced with scientific rigorousness. Experts can determine a specific ratio about what quantitative level is sufficient to protect the government from the opportunistic behaviour of the promoter. Moreover, the role of the lenders can be also taken into consideration in a GDG case. Properly bridging the theoretical gap would provide them with comprehensive knowledge and the capability to apply the findings and suggestions in the case study to specific contexts in their own countries.

Academically, the valuable experience distilled from the case study approach is interpreted in light of the TCE. Subsequently, the game theory methodology is adopted. Unlike superficial reasoning based on intuition, the game equilibrium view of GDG as well as case study evidence convincingly support the conclusions of this study. The proposed methodologies and research flow for combining case study, TCE and game theory provide researchers in construction field a useful tool for analysing similar contractual issues. Future studies may apply the proposed methodologies and research flow for indepth analysis of opportunistic promoter behaviour in the operation phase of PPPs with GDG. Such studies could reveal measures complementary to GDG in different stages of a PPP life cycle. 


\section{References}

Aoki, M. 2008. Analysing institutional change: integrating endogenous and exogenous views, in Kornai, J.; Mátyás, L.; Roland, G. (Eds.). Institutional change and economic behaviour. New York: Palgrave Macmillan, 113-133.

Askar, M. M.; Gab-Allah, A. A. 2002. Problems facing parties involved in build, operate, and transport projects in Egypt, Journal of Management in Engineering 18(4): 173-178. http://dx.doi.org/10.1061/(ASCE)0742597X(2002)18:4(173)

Bakatjan, S.; Arikan, M.; Tiong, R. L. K. 2003. Optimal capital structure model for BOT Power projects in Turkey, Journal of Construction Engineering and Management 129(1): 89-97. http://dx.doi.org/10.1061/(ASCE)07339364(2003)129:1(89)

Carmichael, F. 2005. A guide to game theory. Harlow: Financial Times Prentice Hall. 286 p.

Carrillo, P.; Robinson, H.; Foale, P.; Anumba, C.; Bouchlaghem, D. 2008. Participation, barriers, and opportunities in PFI: the United Kingdom experience, Journal of Management in Engineering 24(3): 138-145. http://dx.doi.org/10.1061/(ASCE)0742597X(2008)24:3(138)

Chan, A. P. C.; Lam, P. T. I.; Chan, D. W. M.; Cheung, E.; Ke, Y. 2010. Potential obstacles to successful implementation of public-private partnerships in Beijing and the Hong Kong special administrative region, Journal of Management in Engineering 26(1): 30-40.

http://dx.doi.org/10.1061/(ASCE)0742597X(2010)26:1(30)

Chang, C.-Y.; Ive, G. 2007. The hold-up problem in the management of construction projects: a case study of the Channel Tunnel, International Journal of Project Management 25(4): 394-404.

http://dx.doi.org/10.1016/j.ijproman.2007.01.001

Chen, C.; Doloi, H. 2008. BOT application in China: driving and impeding factors, International Journal of Project Management 26(4): 388-398.

http://dx.doi.org/10.1016/j.ijproman.2007.07.002

Cheung, E.; Chan, A. P. C.; Kajewski, S. 2010. The public sector's perspective on procuring public works projects comparing the views of practitioners in Hong Kong and Australia, Journal of Civil Engineering and Management 16(1): 19-32. http://dx.doi.org/10.3846/jcem.2010.02

Chiang, Y.-H.; Cheng, E. W. L. 2009. Perception of financial institutions toward financing PFI projects in Hong Kong, Journal of Construction Engineering and Management 135(9): 833-840. http://dx.doi.org/10.1061/(ASCE)07339364(2009)135:9(833)

Chowdhury, A. N.; Charoenngam, C. 2009. Factors influencing finance on IPP projects in Asia: a legal framework to reach the goal, International Journal of Project Management 27(1): 51-58.

http://dx.doi.org/10.1016/j.ijproman.2008.01.011

Devapriya, K. A. K. 2006. Governance issues in financing of public-private partnership organisations in network infrastructure industries, International Journal of Project Management 24(7): 557-565.

http://dx.doi.org/10.1016/j.ijproman.2006.07.003

DORTS (Department of Rapid Transit Systems). 2011. Network [online], [cited 18 November 2011]. Available from Internet:

http://english.dorts.taipei.gov.tw/ct.asp?xItem=205656\&ct Node $=19582 \& m p=115002$
Dougma, S.; Schreuder, H. 2002. Economic approaches to organizations. Harlow: Pearson Education Limited. 282 p.

Dudkin, G.; Välilä, T. 2005. Transaction costs in public-private partnerships: a first look at the evidence. Economic and Financial Report 2005/03, European Investment Bank.

Gibbons, R. 1992. A primer in game theory. Harlow: Pearson Education Limited. $288 \mathrm{p}$.

Grunegerg, S. L.; Ive, G. J. 2000. The economics of the modern construction firm. Macmillan Press Ltd. 307 p. http://dx.doi.org/10.1057/9780230510432

HM TREASURY. 2009. Treasury lending to PFI projects and the Treasury's Infrastructure Finance Unit [Online], [cited 10 June 2011]. Available from Internet: http://webarchive.nationalarchives.gov.uk/201004070108 52/http:/www.hm-treasury.gov.uk/ppp_tifu_index.htm

Ho, S. P.; Hsu, Y.; Lin, E. 2011. Model for knowledge-sharing strategies: a game theory analysis, Engineering Project Organization Journal 1(1): 53-65.

http://dx.doi.org/10.1080/21573727.2010.549610

Ho, S. P.; Tsui, C. 2010. When are public-private partnerships not an appropriate governance structure? Case study evidence, in Proceedings of Construction Research Congress 2010, 8-10 May, 2010, Banff, Canada, 817826. http://dx.doi.org/10.1061/41109(373)82

Ho, S. P. 2006. Model for financial renegotiation in PublicPrivate Partnership Projects and its policy implications: game theoretic view, Journal of Construction Engineering and Management 132(7): 678-688.

http://dx.doi.org/10.1061/(ASCE)07339364(2006)132:7(678)

Ho, S. P.; Liu, L. Y. 2002. An option pricing-based model for evaluating the financial viability of privatized infrastructure projects, Construction Management and Economics 20(2): 143-156. http://dx.doi.org/10.1080/01446190110110533

Irwin, T. C. 2007. Government guarantees - allocating and valuing risk in privately financed infrastructure projects. Washington, DC: World Bank. $230 \mathrm{p}$. http://dx.doi.org/10.1596/978-0-8213-6858-9

Li, N. N. T. 1998. Keeping Taiwan connected - the new high speed rail [online], [cited 5 May 2011]. Available from Internet: http://www.prac.org/materials/1998_Taipei/ TaiwanHSR.html

Mandri-Perrott, C.; Menzies, I. 2010. Private sector participation in light rail-light metro transit initiatives. Washington, D.C.: The World Bank. 324 p. http://dx.doi.org/10.1596/978-0-8213-8085-7

Marin, P. 2009. Public-Private Partnerships for urban water utilities - a review of experience in developing countries. Washington, D.C.: The World Bank. 208 p. http://dx.doi.org/10.1596/978-0-8213-7956-1

McCain, R. A. 2004. Game theory: a non-technical introduction to the analysis of strategy. Mason, Ohio: Thomson/South-Western. $391 \mathrm{p}$.

Medda, F. 2007. A game theory approach for the allocation of risks in transport public private partnerships, International Journal of Project Management 25(3): 213-218. http://dx.doi.org/10.1016/j.ijproman.2006.06.003

MOTC (Ministry of Transportation and Communication). 2010. Taiwan High Speed Rail (HSR) projects [Online], [cited 5 May 2011]. Available from Internet: www.hsr.gov.tw/homepage.nsf/2274ba1db71bcceb48256 921002b7f08/824eef7a368d87264825729800391614?Ope nDocument 
Ng, S. T.; Xie, J.; Skitmore, M.; Cheung, Y. K. 2007. A fuzzy simulation model for evaluating the concession items of public-private partnership schemes, Automation in Construction 17(1): 22-29.

http://dx.doi.org/10.1016/j.autcon.2007.02.010

North, D. C. 1990. Institutions, institutional change and economic performance. New York: Cambridge University Press. 159 p. http://dx.doi.org/10.1017/CBO9780511808678

Ock, J. H.; Han, S. H.; Park, H. K.; Diekmann, J. E. 2005. Improving decision quality: a risk-based go/no-go decision for build-operate-transfer (BOT) projects, Canadian Journal of Civil Engineering 32(3): 517-532. http://dx.doi.org/10.1139/105-002

OECD (Organisation for Economic Co-operation and Development). 2007. OECD Principles for Private Sector Participation in Infrastructure. Paris: OECD Publications. $32 \mathrm{p}$.

PMI (Project Management Institute) 2004. A guild to the project management body of knowledge (PMBOK Guide). Pennsylvania: Project Management Institute. 459 p.

PPIAF (Public-Private Infrastructure Advisory Facility) 2009. Toolkit for Public-Private Partnerships in roads and highways (updated in 2009) [online], [cited 15 November 2011]. Available from Internet:

http://www.ppiaf.org/ppiaf/sites/ppiaf.org/files/documents /toolkits/highwaystoolkit/3/3-34-3.html

Russell, A. D.; Tawiah, P.; De Zoysa, S. 2006. Project innovation - a function of procurement mode?, Canadian Journal of Civil Engineering 33(12): 1519-1537. http://dx.doi.org/10.1139/106-077

Salman, A. F. M.; Skibniewski, M. J.; Basha, I. 2007. BOT viability model for large-scale infrastructure projects, Journal of Construction Engineering and Management 133(1): 50-63. http://dx.doi.org/10.1061/(ASCE)07339364(2007)133:1(50)

Solino, A. S.; Vassallo, J. M. 2009. Using Public-Private Partnerships to expand subways: Madrid-Barajas international airport case study, Journal of Management in Engineering 25(1): 21-28.

http://dx.doi.org/10.1061/(ASCE)0742597X(2009)25:1(21)

Tang, L.; Shen, Q.; Cheng, E. W. L. 2010. A review of studies on Public-Private Partnership projects in the construction industry, International Journal of Project Management 28(7): 683-694.

http://dx.doi.org/10.1016/j.ijproman.2009.11.009
Tserng, H. P.; Russell, J. S.; Hsu, C. W.; Lin, C. 2012. Analyzing the Role of National PPP unit in promoting PPP using new institutional economics and case study, Journal of Construction Engineering and Management 138(2): 242-249. http://dx.doi.org/10.1061/(ASCE)CO.1943-7862.0000398

Wibowo, A. 2006. CAPM-based valuation of financial government supports to infeasible and risky private infrastructure projects, Journal of Construction Engineering and Management 132(3): 239-248. http://dx.doi.org/10.1061/(ASCE)07339364(2006)132:3(239)

Williamson, O. E. 1996. The mechanisms of governance. Oxford: Oxford University Press. 429 p.

WORLDBANK. 2010. Did you know? Note 12: Investment in road projects with private participation more than doubled between 2005 and 2008, but was concentrated in a few countries. Public-private infrastructure advisory facility. $4 \mathrm{p}$.

Xu, Y.; Yeung, J. F. Y.; Chan, A. P. C.; Chan, D. W. M.; Wang, S. Q.; Ke, Y. 2010. Developing a risk assessment model for PPP projects in China - a fuzzy synthetic evaluation approach, Automation in Construction 19(7): 929-943. http://dx.doi.org/10.1016/j.autcon.2010.06.006

Yuan, J.-F.; Skibniewski, M. J.; Li, Q.; Shan, J. 2010. The driving factors of China's Public-Private Partnership projects in metropolitian transportation systems: public sector's viewpoint, Journal of Civil Engineering and Management 16(1): 5-18. http://dx.doi.org/10.3846/jcem.2010.01

Yun, S.; Han, S. H.; Kim, H.; Ock, J. H. 2009. Capital structure optimization for build-operate-transfer (BOT) projects using a stochastic and multi-objective approach, Canadian Journal of Civil Engineering 36(5): 777-790. http://dx.doi.org/10.1139/L08-134

Zhang, X.; Abourizk, S. M. 2006. Determining a reasonable concession period for private sector provision of public works and service, Canadian Journal of Civil Engineering 33(5): 622-631. http://dx.doi.org/10.1139/106-010

Zhang, X. 2005. Financial viability analysis and capital structure optimization in privatized public infrastructure projects, Journal of Construction Engineering and Management 131(6): 656-668.

http://dx.doi.org/10.1061/(ASCE)07339364(2005)131:6(656)

Hui Ping TSERNG. He is a Full Professor at the Department of Civil Engineering of National Taiwan University. He is also a Corresponding Member of Russian Academy of Engineering. He has a PhD degree in Construction Engineering and Management from University of Wisconsin-Madison and he is an Official Reviewer or Editorial Board Member of several international journals. His research interests include advanced techniques for project management, construction finance, knowledge management, management information system, GPS/wireless Sensor Network, and automation in construction.

Shih-Ping HO. He is an Associate Professor of Construction Management at National Taiwan University. He taught at Stanford University in 2010 as endowed Shimizu Visiting Associate Professor. He is on the Editorial Board of Engineering Project Organization Journal. His research focuses on game theory modelling and analysis, the internationalization of A/E/C firms, the governance of Public-Private Partnerships (PPPs), strategic management, and knowledge sharing.

Jui-Sheng CHOU. He is a Full Professor at the Department of Civil and Construction Engineering of National Taiwan University of Science and Technology. He has over a decade of experience in project management and consulting services for the private and public sectors. He also serves as a Committee Member in several international and domestic professional organizations. His teaching and research interests are primarily involved in Project Management related to knowledge discovery in databases, quantitative methods, decision, risk \& reliability, cost management, hazard mitigation in spatial planning practice, and sustainable development. 
Chieh LIN. As a Deputy Director for the Department of Technology of the Taiwan Government (R.O.C.), he was responsible not only for enacting, regulating, and promoting Public-Private Partnerships (PPP)/Government Procurement (GP) policy, but also for planning, reviewing, coordinating, and supervising PPP/GP projects. He received his MS in Construction Economics and Management from the London College. He has over a decade of experience in promoting PPP for the public sector. He has professional licenses in both civil and geotechnical engineering. He was a part-time PhD student in the Department of Civil Engineering at National Taiwan University during 2009-2013. Because of his unique work experience, his primary research interests are PPP and GP, including financial assessment, contractual design and project management. 